\title{
Focal seizures in a patient with myotonic disorder type 2 co-segregating with a chloride voltage-gated channel 1 gene mutation: a case report
}

\author{
Leema Reddy Peddareddygari ${ }^{1}$, Arman Singh Grewal ${ }^{1}$ and Raji Paul Grewal ${ }^{2 *}$
}

\begin{abstract}
Background: Myotonic dystrophy type 2 is a multisystem disorder with both neurological and non-neurological signs and symptoms. Seizures are not a commonly associated neurological feature of this disorder.

Case presentation: A 57-year-old white American man presented with a long history of clinical and electrophysiological features of a myotonic disorder. He also developed multiple episodes of focal seizures and underwent a series of investigations which showed no structural or metabolic etiology. Genetic testing revealed that he had an expansion mutation in CCHC-type zinc finger, nucleic acid binding protein gene confirming the diagnosis of myotonic disorder type 2 and carried a mutation in the chloride voltage-gated channel 1 gene.
\end{abstract}

Conclusions: We report a rare association between myotonic dystrophy type 2 and a seizure disorder. The pathophysiology of a possible relationship between these two neurological conditions is discussed.

Keywords: Myotonic dystrophy type 2, Seizures, Myotonia, CNBP and CLCN1 gene mutations, Case report

\section{Background}

The myotonic dystrophies are a group of genetic disorders characterized by both neurological and nonneurological manifestations [1]. Myotonic dystrophy type 1 (DM1) is caused by (CTG)n repeat expansions in 3' untranslated region of the dystrophia myotonica protein kinase (DMPK) gene, while myotonic dystrophy type 2 (DM2) is caused by a tetranucleotide repeat (CCTG)n in the first intron of the CCHC-type zinc finger, nucleic acid binding protein (CNBP) gene.

Progressive weakness and myotonia are common neurological features in both DM1 and DM2; however, seizures are not typically associated with either of these disorders. We report the case of a patient with genetically confirmed myotonic dystrophy co-segregating with a chloride voltage-gated channel 1 (CLCN1) gene mutation and partial seizures.

\footnotetext{
* Correspondence: RGrewal@stfrancismedical.org

${ }^{2}$ Neuroscience Institute, Saint Francis Medical Center, 601 Hamilton Avenue, Trenton, NJ, USA

Full list of author information is available at the end of the article
}

\section{Case presentation}

We describe the case of a 57-year-old white American man with a history of weakness who presented for genetic confirmation of a myotonic disorder. He had been evaluated and diagnosed as having a myotonic disorder at age 27 years when he presented for complaints of stiffness. This diagnosis was made after an electromyography (EMG) test was performed. Over the ensuing 30 years, he developed proximal muscle weakness more marked in his legs than arms with no other significant neurological complaints. A neurological examination at age 57 years showed no abnormalities of his mental status; a cranial nerve examination and cerebellar testing showed no abnormalities, and a sensory examination testing proprioception, vibration, light touch, and pin prick sensibility showed no abnormalities. $\mathrm{He}$ had normoactive reflexes with flexor plantar responses. An examination of power revealed Medical Research Council (MRC) grade 4/5 weakness in tests of internal and external rotation, and in deltoid, biceps, and hip flexion. In the remaining muscles, he had normal 
strength. His muscle bulk was normal and although he had no percussion myotonia, there was a delay in releasing a handshake consistent with action-induced myotonia. Tests of gait were normal.

There was no family history of anyone with a similar disorder but his father died at age 56 years from heart disease and there was no other history available on the paternal side. His paternal ancestors came from Romania but originally were of German descent. His mother died at age 94 years from breast cancer and had no clinical features to suggest she was affected by a myotonic disorder.

Multiple recent EMGs had been performed showing the presence of myotonic discharges with no convincing evidence of myopathy. Genetic testing was performed confirming a diagnosis of DM2, an additional mutation was also detected in his CLCN1 gene (refer to Genetic testing subsection).

He was seen in follow up and several years after the confirmation of the diagnosis, he presented with four episodes of mild weakness of his right arm, leg and face associated with numbness and tingling in the same distribution. He also developed slurring of his speech during these episodes which lasted for approximately 2 minutes following a return to his baseline in 10 minutes. He initially went to our emergency room where a diagnosis of transient ischemic attack was made and investigations were performed including a cerebral magnetic resonance imaging and magnetic resonance angiography, carotid ultrasound, and an echocardiogram. All these tests and routine serum chemistries were normal or negative. These episodes recurred three more times over a course of 6 months. The episodes were stereotypical with no clear initiating event and with full recovery to baseline within 10 minutes. A repeat neurological examination showed no significant change from that initially performed. A routine electroencephalogram (EEG) was done 1 month after the last episode showing slowing in his left cerebral hemisphere with no other abnormality detected. He was diagnosed with focal seizures. Approximately 4 months after the last episode, a repeat routine EEG was done and was normal. This was followed up with a 48-hour EEG recording which was also normal. Over the course of the next 24 months, no further seizure episodes were noted without him taking an anticonvulsant medication.

\section{Genetic testing}

Genetic testing was performed by a commercial company and analysis for expansions in the DMNK and CNBP genes. However, since he had a prior diagnosis of myotonia congenita, analysis of the skeletal muscle chloride channel, $C L C N 1$ gene was also performed. The results showed no genetic evidence for DM1; testing for DM2 showed a mutant-expanded intronic allele of greater than 372 CCTG repeats with the wild-type allele of 140 repeats in $C N B P$ gene. In addition, a heterozygous mutation in the CLCN1 was also detected, rs149729531, c.501C>G, p.F167L.

\section{Discussion}

Our patient has genetically confirmed DM2 with an associated CLCN1 mutation. It is likely that he inherited the mutation from his father who died relatively young and for whom there is little history available. Alternatively, it may represent a spontaneous mutation. Mutations in the CLCN1 gene can cause either autosomal dominant Thomsen's type myotonia or recessive Becker's type. It is interesting that a number of patients with DM2 co-segregating heterozygous recessive mutations in CLCN1 have been reported [2]. It has been suggested that the patients with DM2 without the associated CLCN1 mutations are less likely to seek medical attention perhaps indicating that in them, the disease is less phenotypically severe. Recently there have been two case reports of patients with DM who had seizures. The first is that of a patient with the clinical features of DM and epilepsy but without genetic confirmation of diagnosis [3]. In another study, a patient with genetically confirmed DM2 was noted to have a long history of generalized epilepsy [4]. The episodes experienced by our patient are most consistent with focal seizures without impairment of consciousness or awareness [5]. Our patient is the first to be described with partial seizures associated with mutations in both the CNBP and CLCN1 genes. The specific mutation in the CLCN1 gene in our patient has been previously reported in individuals with Becker's type or recessive generalized myotonia [6].

There are several links between myotonic disorders and epilepsy. Both are episodic disorders and the treatment of myotonia can include anti-epilepsy medications [7]. The CNBP gene is expressed in both peripheral and central nervous system tissues [1]. Until recently, it was thought that the chloride channel protein 1 (ClC-1) protein, the product of the CLCN1 gene, was not expressed in brain tissue. However, a recent report suggests that $C L C N 1$ is expressed in the mouse thalamus and cortex [8]. In this study, in addition to this animal data, a patient with epilepsy is presented. A mutation in the CLCN1 gene is reported and it is hypothesized that this disease-producing mutation is the cause of the seizure disorder in this patient [9]. This supports other research that indicates that there is significant variability in CLCN1 transcripts in both muscle and brain tissues that could contribute to the phenotypic variability observed in patients with myotonic disorders $[8,10]$. 
In our patient, it is possible that the mutations in $C N B P$ or $C L C N 1$ genes alone or in combination are involved in the pathophysiology of the seizure.

\section{Conclusions}

This report describes the rare case of a patient with mutations in CNBP and CLCN1 genes presenting with DM2 and a seizure disorder. This co-occurrence of these two episodic disorders could indicate a shared pathophysiology.

\section{Abbreviations}

CIC-1, chloride channel protein 1; CLCN1, chloride voltage-gated channel 1 gene; CNBP, CCHC-type zinc finger, nucleic acid binding protein gene; DM1 myotonic dystrophy type 1; DM2, myotonic dystrophy type 2; DMPK, dystrophia myotonica protein kinase; EEG, electroencephalogram; EMG, electromyography; MRC, Medical Research Council

\section{Acknowledgements}

We would like to thank the patient for participation in this study.

\section{Authors' contributions}

RPG supervised all aspects of this study and contributed to the writing of clinical aspects of the study. ASG performed a literature search and participated in writing the manuscript. LRP reviewed the genetic data, reviewed and critiqued the manuscript. All authors read and approved the final manuscript.

\section{Authors' information}

Leema Reddy Peddareddygari is Scientific Director, Neuro-genetics Institute. Arman S. Grewal is in the Kinesiology Program, Queens University, Kingston, Canada.

Raji P. Grewal is a Professor of Neuroscience at Seton Hall University, New Jersey, USA and a Neuromuscular Neurologist.

\section{Competing interests}

The authors declare that they have no competing interests.

\section{Consent for publication}

Written informed consent was obtained from our patient for the publication of this case report. A copy of the written consent is available for review by the Editor-in-Chief of this journal.

\section{Author details}

'The Neuro-genetics Institute, 501 Elmwood Ave, Sharon Hill, PA, USA.

${ }^{2}$ Neuroscience Institute, Saint Francis Medical Center, 601 Hamilton Avenue,

Trenton, NJ, USA.

Received: 13 April 2016 Accepted: 24 May 2016

Published online: 07 June 2016

\section{References}

1. Rajavashisth TB, Taylor AK, Andalibi A, Svenson KL, Lusis AJ. Identification of a zinc finger protein that binds to the sterol regulatory element. Science. 1989;245(4918):640-3.

2. Suominen T, Schoser B, Raheem O, Auvinen S, Walter M, Krahe R, et al. High frequency of co-segregating CLCN1 mutations among myotonic dystrophy type 2 patients from Finland and Germany. J Neurol. 2008;255(11):1731-6. doi:10.1007/s00415-008-0010-z. Epub 2008 Sep 24.

3. Worku DK. Concurrence of myotonic dystrophy and epilepsy: a case report. J Med Case Rep. 2014;8:427. doi:10.1186/1752-1947-8-427.

4. Cagnetti C, Buratti L, Foschi N, Balestrini S, Provinciali L. Generalized epilepsy in a patient with myotonic dystrophy type 2. Neurol Sci. 2014;35(3):489-90. doi:10.1007/s10072-013-1578-3.

5. Berg AT, Berkovic SF, Brodie MJ, Buchhalter J, Cross JH, van Emde Boas W, et al. Revised terminology and concepts for organization of seizures and epilepsies: report of the ILAE Commission on Classification and
Terminology, 2005-2009. Epilepsia. 2010;51(4):676-85. doi:10.1111/j.15281167.2010.02522x

6. George Jr AL, Sloan-Brown K, Fenichel GM, Mitchell GA, Spiegel R, Pascuzzi RM. Nonsense and missense mutations of the muscle chloride channel gene in patients with myotonia congenita. Hum Mol Genet. 1994;3(11): 2071-2.

7. Ptáček LJ. Episodic disorders: channelopathies and beyond. Annu Rev Physiol. 2015;77:475-9. doi:10.1146/annurev-physiol-021014-071922.

8. Chen TT, Klassen TL, Goldman AM, Marini C, Guerrini R, Noebels JL. Novel brain expression of $\mathrm{ClC}-1$ chloride channels and enrichment of CLCN1 variants in epilepsy. Neurology. 2013;80(12):1078-85. doi:10.1212/WNL. 0b013e31828868e7.

9. Berkovic SF, Kapur J. Are myotonia and epilepsy linked by a chloride channel? Neurology. 2013;80(12):1074-5. doi:10.1212/WNL.0b013e3182886a2c. Epub 2013 Feb 13.

10. Ursu SF, Alekov A, Mao NH, Jurkat-Rott K. ClC1 chloride channel in myotonic dystrophy type 2 and CIC1 splicing in vitro. Acta Myol. 2012;31(2):144-53.
Submit your next manuscript to BioMed Central and we will help you at every step:

- We accept pre-submission inquiries

- Our selector tool helps you to find the most relevant journal

- We provide round the clock customer support

- Convenient online submission

- Thorough peer review

- Inclusion in PubMed and all major indexing services

- Maximum visibility for your research

Submit your manuscript at www.biomedcentral.com/submit 